\title{
Bowel in Chest: Type IV Hiatal Hernia
}

\author{
William Krause, MD; Jennifer Roberts, MD; and Romel J. Garcia-Montilla, MD
}

A man, age 81 years, presented with frequent nausea and non-bloody vomiting for the past week, and a 3-day history of worsening epigastric abdominal pain with no flatus or bowel movements. He was tachycardic (120 bpm) and hypotensive $(86 / 40 \mathrm{~mm} \mathrm{Hg})$. Upper abdomen was profoundly tender and distended. Laboratory results were significant for leukocytosis $\left(20 \times 10^{3} / \mathrm{uL}\right.$; normals $4.1-$ $10.9 \times 10^{3} / \mathrm{uL}$ ), acute kidney injury (creatinine $1.8 \mathrm{mg} / \mathrm{dL}$; normals $0.6-1.3 \mathrm{mg} / \mathrm{dL}$ ), and lactic acidosis (lactate $6.0 \mathrm{mmol} / \mathrm{L}$; normals $0.5-2.1 \mathrm{mmol} / \mathrm{L}$ ). Chest radiograph demonstrated air-filled loops of the colon over the midline of the lower thorax (figure 1). Abdominal computed tomography confirmed type IV hiatal hernia (figures 2 and 3). The patient received aggressive hemodynamic resuscitation in the intensive care unit. Exploratory laparotomy with hernia reduction and extended right hemicolectomy, due to extensive colonic necrosis, was performed. Gastrostomy tube was placed.

Four types of hiatal hernias have been described (Table 1), with type IV being the least common. The combination of types II, III, and IV account for around $5 \%$ of all hiatal hernias, but type IV represents only $2-5 \%$ of those. ${ }^{1}$ Type IV are

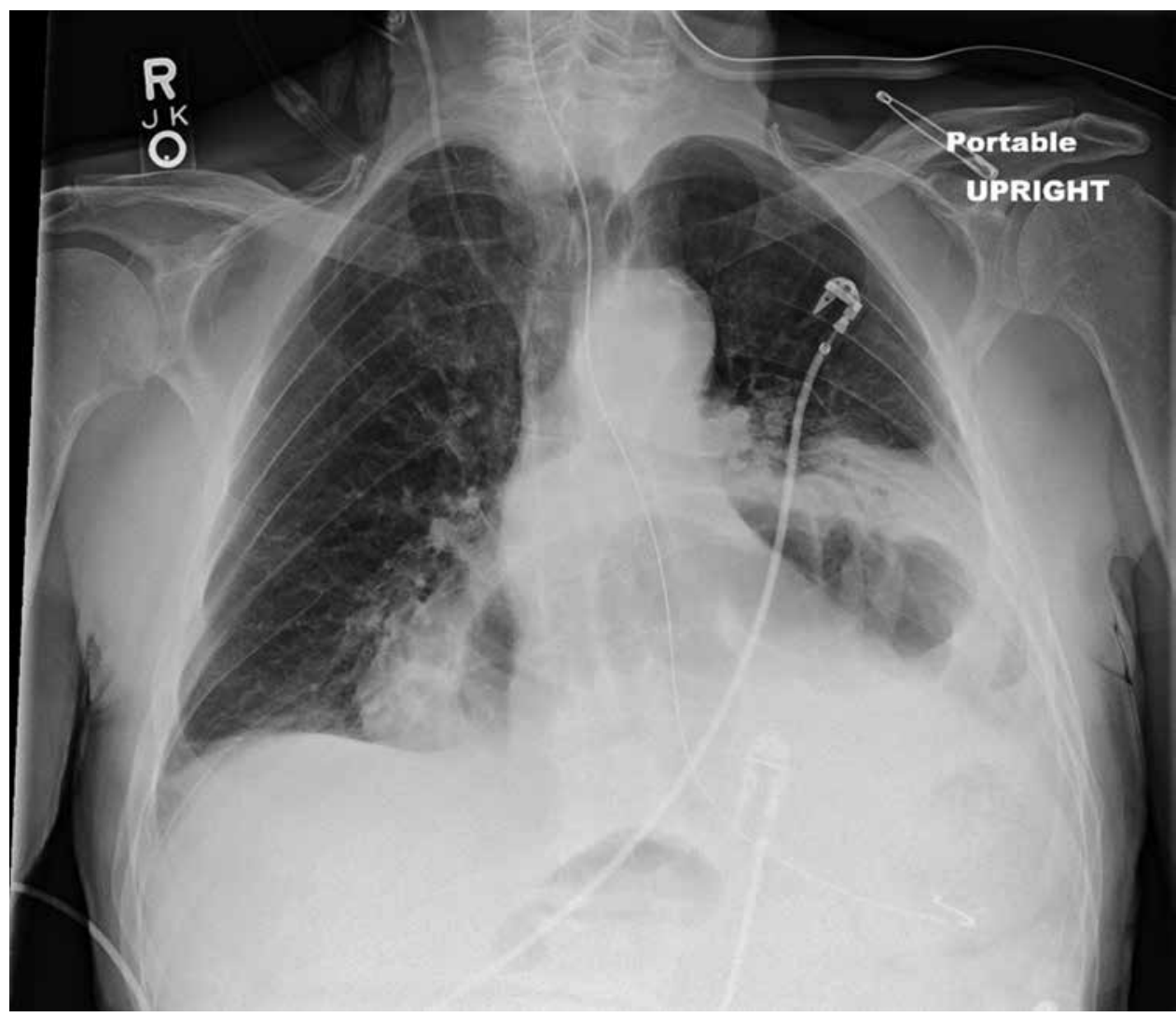

Figure 1. Portable upright chest radiograph showing loops of colon in the thoracic cavity.

Correspondence to: Dr. Romel Garcia-Montilla, Department of Trauma Surgery, Marshfield Clinic, 1000 North Oak Avenue, Marshfield,WI 54449 USA,

Tel: 7I5-387-5796, Email: garcia-montilla.romel@marshfieldclinic.org
Received: May 20, 2016

Accepted: June 10,2016

doi: $|0.3| 2 \mid / \mathrm{cmr} .2016 .1332$
Keywords: Hiatal Hernia;

Complications;

Bowel Repair 


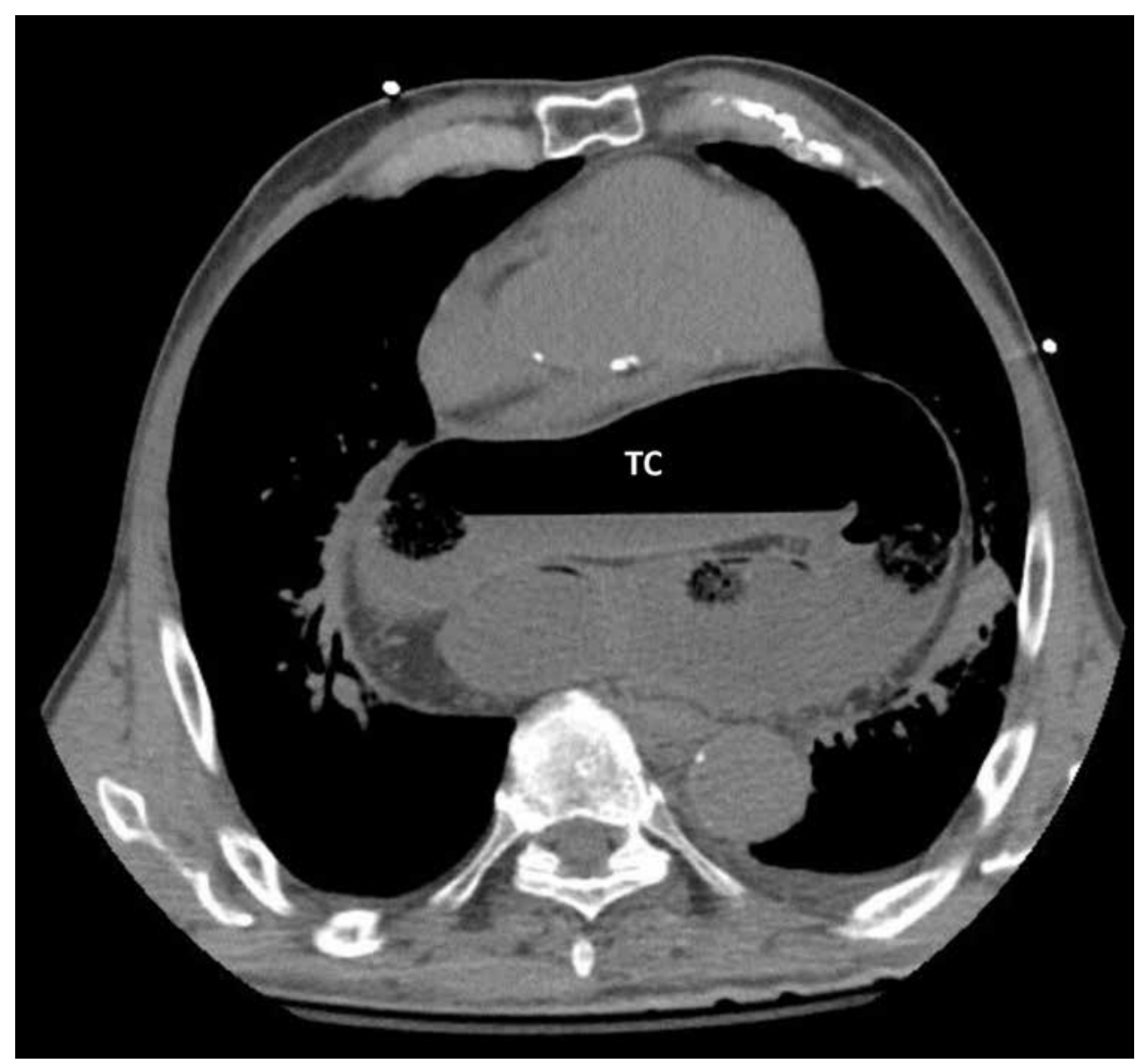

Figure 2. Computed tomography imaging of the thorax showing a large hiatal hernia containing essentially all the transverse colon (TC) which is distended with air fluid levels and thickening of its wall, indicating incarceration.

associated with a large defect in the phrenoesophageal membrane and abnormal laxity of the gastrosplenic and gastrocolic ligaments, which allows parts of the stomach and other intra-abdominal organs to enter the hernia sac., ${ }^{2,3}$ It is unknown if these predisposing abnormalities are acquired, congenital, or a combination of both. ${ }^{3}$ In our case, the defect allowed migration of, not only part of the stomach, but almost all the entire transverse colon into the hernia sac, causing ischemia and necrosis.

Clinical manifestations of large hiatal hernias are unspecific, making their clinical diagnosis challenging. Symptoms vary from minimal epigastric discomfort and fullness to progressive dysphagia, chest discomfort, dyspnea, nausea, vomiting, and severe epigastric and chest pain. ${ }^{4}$ Their natural course can become complicated by volvulus, incarceration, perforation, or even recurrent pneumonia due to dysphagia and frequent vomiting with aspiration. ${ }^{5}$ As with our patient, incarceration or strangulation of the stomach and/or bowels may present as a life threating complication..$^{5}$ If the large hiatal hernia is detected early in the course of the natural evolution, elective surgical repair is recommended, because emergent surgery has been associated with acute organ failure with poor outcomes and a reported mortality rate of up to $56 \%$ in some series. ${ }^{6,7}$ If left untreated, severe complications like outlet gastric obstruction, severe gastroesophageal reflux, and gastric or bowel strangulation may develop in up to $45 \%$ of patients in some reports (Table 1). ${ }^{6,8}$

Giant hiatal hernias are very infrequent, and their spectrum of clinical manifestations is large. Patients can present with minimal signs and symptoms or, as in this case, in extremis. The astute clinician must be aware of the existence of these oddities, including them in the differential diagnosis workup of patients with chest and/or upper abdominal pain, to implement in a timely manner the most appropriate intervention, which can range from only medical treatment to either elective surgical repair or emergent surgical correction.

\section{References}

1. Abbara S, Kalan MM, Lewicki AM. Intrathoracic stomach revisited. AJR Am J Roentgenol 2003;181:403-414.

2. Dean C, Etienne D, Carpentier B, Gielecki J, Tubbs RS, Loukas M. Hiatal hernias. Surg Radiol Anat 2012;34:291-299.

3. Landreneau R, Del Pino M, Santos R. Management of paraesophageal hernias. Surg Clin North Am 2005;85:411-432.

4. Davis SS Jr. Current controversies in paraesophageal hernia repair. Surg Clin North Am 2008;88:959-978. 


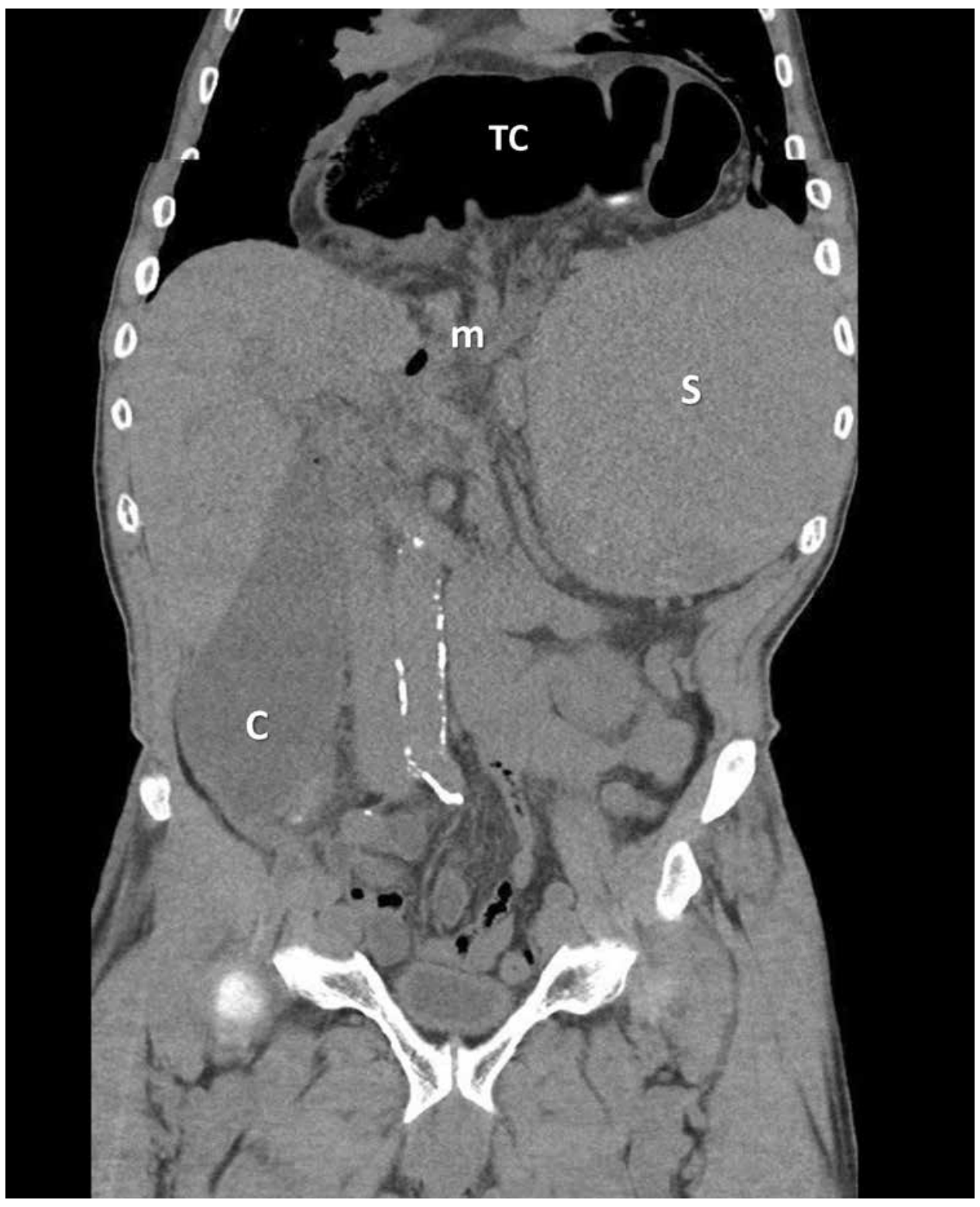

Figure 3. Coronal computed tomography imaging showing a large hiatal hernia with incarcerated transverse colon (TC). The colonic mesenterium $(\mathrm{m})$ and a dilated cecum $(\mathrm{C})$ are observed. Dilated stomach $(\mathrm{S})$ due to gastric outlet obstruction is also observed.

5. Rashid F, Thangarajah T, Mulvey D. A review article on gastric volvulus: a challenge to diagnosis and management. Int J Surg 2010;8:18-24.

6. Stylopoulos N, Gazelle GS, Rattner DW. Paraesophageal hernias: operation or observation? Ann Surg 2002;236:492-500; discussion 500-501.

7. Kohn GP, Price RR, Demeester S, Zehetner J, Muensterer OJ, Awad ZT, Mittal SK, Richardson WS, Stefanidis D, Fanelli RD; SAGES Guidelines Committee. The Society of American Gastrointestinal and Endoscopic Surgeons (SAGES). Guidelines for the Management of Hiatal Hernias. Available at: http://www.sages.org/ publications/guidelines/guidelines-for-the-managementof-hiatal-hernia/. Accessed December 12, 2015.
8. Polomsky M, Hu R, Sepesi B, O`Connor M, Qui X, Raymond DP, Litle VR, Jones CE, Watson TJ, Peters HJ. A population-based analysis of emergent vs. elective hospital admissions for an intrathoracic stomach. Surg Endosc 2010;24:1250-1255

9. Maish MS, DeMeester SR. Paraesophageal hernia. In: Cameron JL. Current surgical therapy. $8^{\text {th }}$ ed. Philadelphia: Saunders; 2004. 38. 


\begin{tabular}{|c|c|c|c|c|}
\hline & Type/Illustration & Description & Incidence & Management ${ }^{7}$ \\
\hline 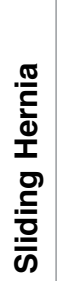 & Type I & $\begin{array}{l}\text { Gastroesophageal (GE) } \\
\text { junction migrates above the } \\
\text { diaphragm. }\end{array}$ & $95 \%$ & $\begin{array}{l}\text { - These are usually asymptomatic and } \\
\text { inconsequential. } \\
\text { - If gastroesophageal reflux disease is } \\
\text { unable to be managed medically, } \\
\text { fundoplication surgery is indicated. }\end{array}$ \\
\hline 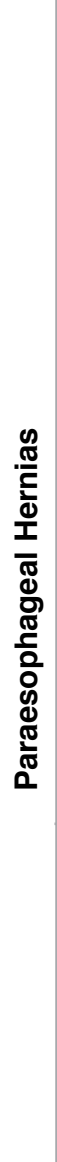 & Type IV & $\begin{array}{l}\text { GE junction in normal } \\
\text { position, but a portion of the } \\
\text { gastric fundus herniates } \\
\text { through the diaphragmatic } \\
\text { hiatus adjacent to esophagus. } \\
\text { Real paraesophageal hernia. }\end{array}$ & $0.4 \%$ & $\begin{array}{l}\text { - Only hernias with real risk for } \\
\text { obstruction. } \\
\text { - If symptomatic should be rapidly repaired } \\
\text { surgically, particularly those with } \\
\text { obstructive symptoms or which have } \\
\text { undergone volvulus. } \\
\text { - Routine elective repair of completely } \\
\text { asymptomatic paraesophageal hernias, } \\
\text { although recommended by some } \\
\text { experts, is debated and may not always } \\
\text { be indicated. } \\
\text { If surgery is considered in asymptomatic } \\
\text { or minimally symptomatic patients, the } \\
\text { patient's age (favoring youngers) and } \\
\text { co-morbidities must be considered. }\end{array}$ \\
\hline
\end{tabular}

\section{Author Affiliations}

William Krause, $M D^{*}$; Jennifer Roberts, $M D^{*}$; and Romel J.

Garcia-Montilla, $\mathrm{MD}^{+}$

*Department of General Surgery, Marshfield Clinic,

Marshfield, Wisconsin, USA

'Department of Trauma Surgery and Surgical Critical Care,

Marshfield Clinic, Marshfield, Wisconsin, USA 